\title{
Comparative Study on the Extent of Damage to Life Quality in Rheumatoid Arthritis Patients with Different Therapeutic Strategies
}

\author{
DIANA IOANA MANUELA TEAHA ${ }^{1 *}$, NICOLETA ANAMARIA PASCALAU2, FLORIN MIHAI MARCU², LIVIU LAZAR ${ }^{1}$ \\ ${ }^{1}$ Doctoral Studies Department, Biomedical Science, 1 University Str., 410087, Oradea, Romania \\ ${ }^{2}$ Faculty of Medicine and Pharmacy, Department of Medicine-Psycho-Neuroscience and Recovery, 10, 1 Decembrie Sq., 410068, \\ Oradea, Romania
}

Rheumathoid Arthritis affects more that 17.6 million of people worldwide [1]. Along with the diagnosis of Rheumatoid Arthrits (RA) comes a big change in patients life. The aim of this study was to evaluate the impact of disease stage or evolution on the patients quality of life, comparing 4 different therapeutic strategies, pursuing HAQ score and VAS (visual analogue pain scale).

Keywords: Rheumatoid Arthritis, Quality of Life, Different Treatments, HAQ score, Biological therapy

Rheumatoid arthritis (RA) affects $1 \%$ of general global population. The pathology is characterized as an erosive synovitis with chronic pattern that progresses into a systemic affection. The extraarticular events include: rheumatoid nodules, rheumatoid vasculitis, amyloidosis, osteoporosis, Sjogren syndrome or Felty synodrome [1-8]. RA leads to permanent damage of the cartilages and articulations, with a major impact on patients quality of life and maybe more important, life expectancy. Most patients reduce their daily activity to match their current capabilities, they withdraw from their social lifes and isolate themselves. It's easy to understand why the target of RA therapy must include an improvement of patients life quality besides obtaining clinical response in slowing down the progression of the disease or in best cases the state of RA remmision $[3,5,9,10]$.

\section{Experimental part}

Material and method

The statistical analysis was done using the SPSS 19. Parametric mean values, frequency ranges, standard deviations, statistical significance tests by the Student method ( $\mathrm{t}$ test).

Sensitivity to change can be assessed in various types of clinical research or long-term observational studies. To measure sensitivity to change, we used the statistical calculation system effect width (ES). ES is a method of standardizing the magnitude of changing a variable after a determined period of time. It represents the mean of change for a variable expressed in standard deviation units. This standardization allows the comparison of values of change of a variable in a study.

136 patients with rheumatoid arthritis were studied in the period 2015-2017.

Patients were followed up for one year with 3 assessments: initially at 6 months and 12 months.

We followed the evolution of patients according to the type of treatment, as follows:

- Group 1 - MTx monotherapy - 34 patients

- Group 2 - MTX + Biological - 28 patients

- Group 3 - MTX + corticotherapy - 34 patients

- Group 4 - MTX + PKT - 40 patients

The groups were formed mainly by female individuals (85.29\% MTX monotherapy, $85.71 \%$ MTX+ Biological therapy, $88.24 \%$ MTX+ Corticotherapy and $80 \%$ MTX+ PKT), with an average age between 55 and 59 years old. Longest duration of disease is found in the MTX + Biological therapy group, approximately 5.02 years of treatment (Table 1).

Most cases with advanced stages of polyarthritis (stage III and IV) were recorded in patients with MTX + biologically active therapy (42.86\%), insignificantly higher than in the corticosteroid group $(23.53 \%, p=0.108)$, but significantly higher than in the MTX and MTX + PKT monotherapy groups ( $14.71 \%$ and $15.00 \%$ respectively, $p$ $=0.014$ and $p=0.011$ respectively) (Table 2, Fig. 1).

Table 1

GROUP CHARACTERISTICS

\begin{tabular}{|l|c|c|c|c|}
\hline & MTx monotherapy & $\begin{array}{c}\text { MTx+biological } \\
\text { therapy }\end{array}$ & MTx+ corticotherapy & MTx+PKT \\
\hline Sex (female/male) & $85.29 \% / 14.71 \%$ & $85.71 \% / 14.29 \%$ & $88.24 \% / 11.76 \%$ & $80.00 \% / 20.00 \%$ \\
\hline Average age (years) & $57.76 \pm 5.70$ & $59.43 \pm 7.05$ & $57.21 \pm 8.18$ & $55.30 \pm 7.34$ \\
\hline $\begin{array}{l}\text { The average duration of the } \\
\text { disease }\end{array}$ & $2.15 \pm 1.39$ & $5.02 \pm 1.99$ & $2.12 \pm 1.45$ & $1.94 \pm 1.28$ \\
\hline
\end{tabular}


Table 2

DISTRIBUTION OF CASES ACCORDING TO DISEASE STAGE

\begin{tabular}{|l|c|c|c|c|c|c|c|c|}
\hline \multirow{2}{*}{\begin{tabular}{|} 
Stage of disease \\
\multirow{2}{*}{}
\end{tabular}} & \multicolumn{2}{|c|}{ MTx monotherapy } & \multicolumn{2}{c|}{$\begin{array}{c}\text { MTx+biological } \\
\text { therapy }\end{array}$} & \multicolumn{2}{c|}{$\begin{array}{c}\text { MTx+ } \\
\text { corticotherapy }\end{array}$} & \multicolumn{2}{c|}{ MTx+PKT } \\
\cline { 2 - 9 } & No & $\%$ & No & $\%$ & No & $\%$ & No & $\%$ \\
\hline Stage I & 15 & 44.12 & 4 & 14.29 & 16 & 47.06 & 18 & 45.00 \\
\hline Stage II & 14 & 41.18 & 12 & 42.86 & 10 & 29.41 & 16 & 40.00 \\
\hline Stage III & 3 & 8.82 & 8 & 28.57 & 4 & 11.76 & 4 & 10.00 \\
\hline Stage IV & 2 & 5.88 & 4 & 14.29 & 4 & 11.76 & 2 & 5.00 \\
\hline
\end{tabular}

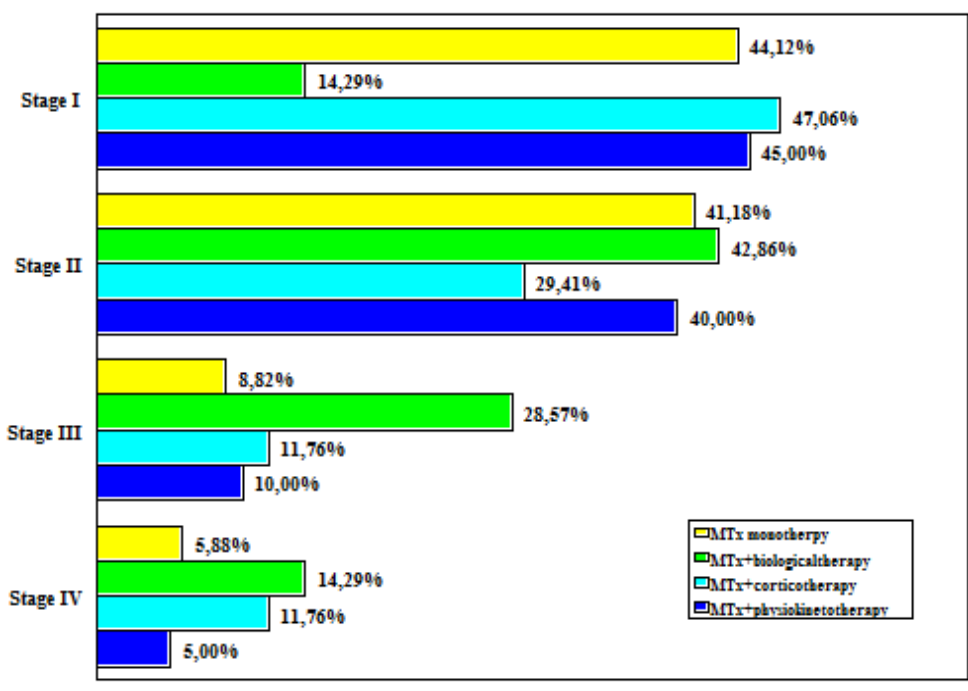

Fig. 1. Distribution of cases according to disease stage

\section{Results and discussions}

The evaluation of patients life quality was quantified following the HAQ score (the health assessment questionnaire) and VAS troughout an year of treatment.

$\mathrm{HAQ}$ is a questionnaire for the assessment of RA, wich evaluates the index of disability showing the grade of dependence/ independece of the patient. The patients autoevaluates it's capabilities, most of the time with the doctor. There are 8 sections: dressing, arising, eating, walking, hygiene, reach, grip, and activities. There are 2 or 3 questions for each section. Scoring within each section is from 0 (without any difficulty) to 3 (unable to do) [11, 12].

One of the most essential and important stage in evaluating patient progress of RA is VAS (visual analogue function scale). In RA is used to evaluate patients amount of pain througout the treatement and stages of disease. It usually presents as a scale from 0-100 or 0-10 in wich the patient and the physician evaluates overall pain [13-15].
Evolution of HAQ score

In contrast to the initial assessment, at 12 months the effect of treatment on the HAQ score was moderate in all groups (MTx monotherapy - ES $=0.57$, MTX + biological $\mathrm{ES}=0.71, \mathrm{MTx}+$ corticotherapy $-\mathrm{ES}=0.71$ and MTx + PKT - ES = 0.58)

Regardless of the applied therapy, in all 4 groups the HAQ score improved significantly at 12 months (MTX monotherapy $-p=0.007$, MTx + biological $-p=0.039$, MTx + corticotherapy - $p=0.002$ and MTx + PKT - $p$ $=0.001)$. (Table 3, fig. .2)

\section{Evolution of VAS}

As compared to the initial assessment, the treatment effect on the VAS score was very good in all groups (MTX monotherapy $-\mathrm{ES}=1.15, \mathrm{MTx}+$ biological $-\mathrm{ES}=1.38$, MTX + corticotherapy $-E S=1.20$ and MTX + PKT - ES = 1.23).

Regardless of the therapy applied, in all 4 groups the VAS score decreased significantly at 12 months ( $p$ $<0.001$ ). (Table 4, fig. 3)

\begin{tabular}{|l|c|c|c|c|}
\hline \multicolumn{1}{|c|}{ Assessment } & $\begin{array}{c}\text { MTx } \\
\text { monotherapy }\end{array}$ & $\begin{array}{c}\text { MTx+biological } \\
\text { therapy }\end{array}$ & $\begin{array}{c}\text { MTx+ } \\
\text { corticotherapy }\end{array}$ & MTx+PKT \\
\hline Initially & $1.35 \pm 0.48$ & $1.46 \pm 0.51$ & $1.42 \pm 0.39$ & $1.31 \pm 0.56$ \\
\hline 6 months & $1.18 \pm 0.35$ & $1.21 \pm 0.37$ & $1.19 \pm 0.31$ & $1.11 \pm 0.40$ \\
\hline 12 months & $1.08 \pm 0.30$ & $1.10 \pm 0.35$ & $1.15 \pm 0.30$ & $0.98 \pm 0.27$ \\
\hline
\end{tabular}

Table 3

EVOLUTION OF HAQ SCORE 


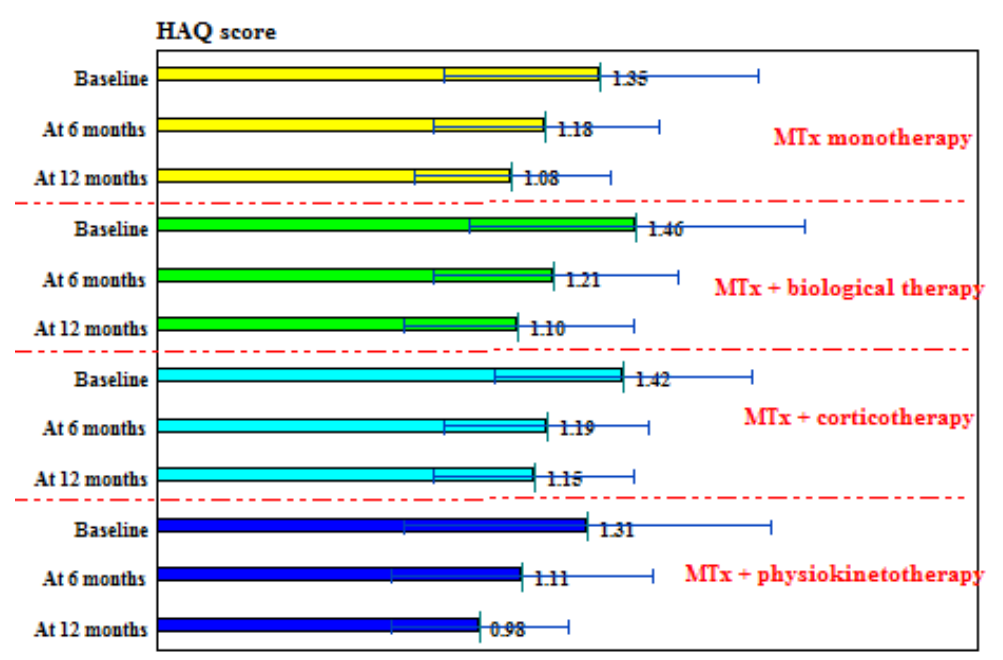

Fig. 2. Evolution of $H A Q$ score

\begin{tabular}{|l|c|c|c|c|}
\hline \multicolumn{1}{|c|}{ Assessment } & $\begin{array}{c}\text { MTx } \\
\text { monotherapy }\end{array}$ & $\begin{array}{c}\text { MTx+biological } \\
\text { therapy }\end{array}$ & MTx+ & corticotherapy \\
\hline Initially & $32.06 \pm 7.26$ & $35.00 \pm 8.28$ & $35.44 \pm 9.05$ & $36.38 \pm 873$ \\
\hline 6 months & $25.44 \pm 7.36$ & $26.61 \pm 8.34$ & $25.59 \pm 8.92$ & $30.25 \pm 10.26$ \\
\hline 12 months & $23.68 \pm 8.43$ & $23.57 \pm 9.66$ & $24.56 \pm 7.65$ & $25.63 \pm 10.67$ \\
\hline
\end{tabular}

Table 4

EVOLUTION OF VAS

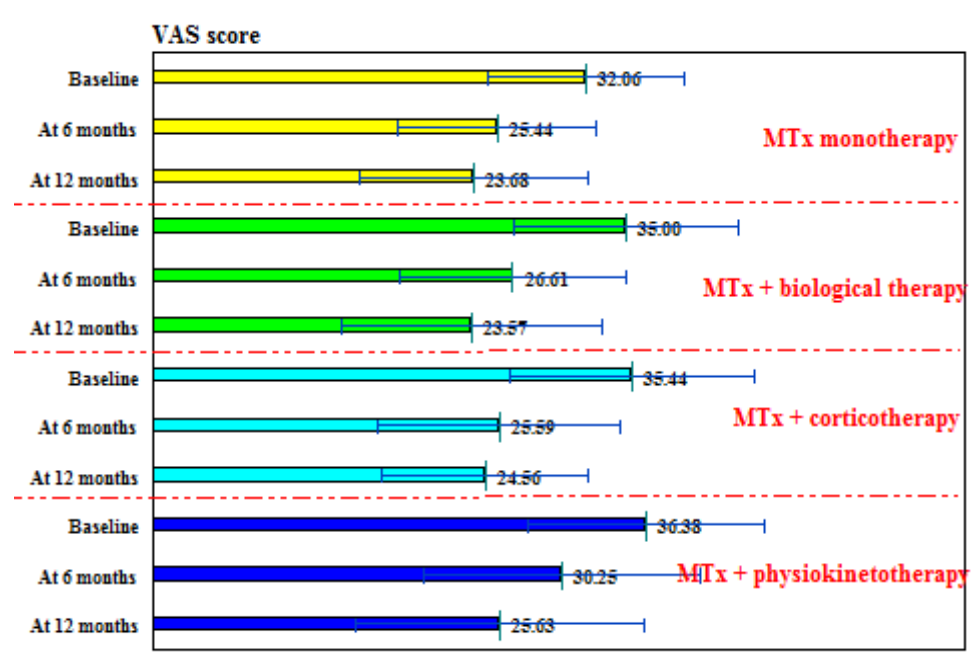

\section{Conclusions}

In contrast to the initial assessment, at 12 months the effect of treatment on the HAQ score was moderate in all groups of treatment, with best results in MTX + biological - $E S=0.71$, respectively MTX + corticotherapy $-E S=0.71$. Regardless of the applied therapy, in all 4 groups the HAQ score improved significantly at 12 months.

As compared to the initial assessment, the treatment effect on the VAS score was very good in all groups, with best results in MTX + biological - ES $=1.38$, followed by $M T X+P K T-E S=1.23)$. Regardless of the therapy applied, in all 4 groups the VAS score decreased significantly at 12 months ( $p<0.001)$.

The following study highlights the importance of clinical treatment in keeping the symptoms of RA under control and improving patients life quality on one hand, and proving the importance of biological and physiokinetotherapy in the overall outcome.

\section{References}

1.*** American College of Rhumatology, 2013. [Online]. Available: http://www.rheumatology.org/.
2. CODRINA A., BALANESCU A., BALASOIU H.D., BUMBACEA B., CONSTANTINESCU O., ENACHE C., GEORGESCU L., MOCIRAN E., PARVU M., PREDEEANU D., REDNIC S., REZUS E., SUTA M., SUTEANU, TANASESCU C., Poliartrita Reumatoida -Ghid de diagnostic si tratament, Brasov, 2007.

3. S, CHANDRASHEKARA, Current studies of biomarkers for the early diagnosis of rheumatoid arthritis, Dovepress, 2014, p. 107-119.

4.HEIJ DE VAN DER D, BREEDVELD FC, KAVANAUGH A., Disease activity, physical function, and radiographic progression after long term therapy with adalimumab plus methotrexate: 5-year results, vol. 37(11), J. Rheumatol, 2010, p. 2237-2246.

5. KLIPPEL J H., LEONG A L., LOCKSHIN M D., VOLCKER B., LORIG K., NELSON J. L., HUTCHINSON F., National Institute of Arthritis and Musculoskeletal and Skin Diseases, August 2014.

6. . DICKSON, P. LANYON, E. WISE, Making a diagnosis of rheumatoid arthritis, 0302 2014. [Online]. Available: http://nras.org.uk/making-adiagnosis-of-rheumatoid-arthritis.

7. KRABBEN A, H. T.,Undifferentiated arthritis characteristics and outcomes when applying the 2010 and 1987 criteria for rheumatoid arthritis, Annals of the rheumatic diseases, pp. 71:238-41., 2012. 8.*** National Rheumatoid Arthritis Society, 02 2014. [Online]. Available: http://nras.org.uk/making-a-diagnosis-of-rheumatoidarthritis. 
9.FINCKLE A, LIANG MH, VAN HERCKENRODE CM, DE PABLO P., Long term impact of early treatment on radiological progression in rheumatoid arthritis: A meta-analysis, Arthritis Rheum, 2006, p. 55:864872.

10.ARNETT F.C., E. S., The American Rheumatism Association 1987 revised criteria for the classification of rheumatoid arthritis., 1988.

11.FRIES JF, SPITZP, KRAINES G, HOLMAN H, Measurement of Patient Outcome in Arthritis, Arthritis and Rheumatism, 1980.

12. RAMEY DR, FRIES JF, SINGH G. IN B. SPILKER, Quality of Life and Pharmacoleconomics in Clinical Trials, 2nd ed, The Health Assessment Questionnaire, Lippincott-Raven Pub, 1996.
13. D. GOULD et al., Visual Analogue Scale (VAS), J ournal of Clinical Nursing, 2001, pp. 10:697-706.

14.*** EC., Huskisson, Measurement of pain, Lancet, 1974, p. 2:112731.

15. G. KAGEYAMA, A. ONISHI, Y. UEDA, Y. KAMEI, H. YAMADA, Y. ICHISE, D. WAKI, I. NAKA, K. TSUDA, T. OKANO, S. TAKAHASHI, M. NISHIDA, K. AKASHI, K. NISHIMURA, S. SENDO, Y. KOGATA, J. SAEGUSA, A. MORINOBU, Some of The Painful RA Patients Underrate Global Health VAS at Hospitals, BMJ Publishing Group Limited, 2006.

Manuscript received: 23.03 .2019 